\title{
INFLUÊNCIA DE HIDROCOLÓIDES NA TEXTURA DE GEL DE AMIDO DE MILHO ${ }^{1}$
}

\author{
Maisa Peixoto MUNHOZ², Fernanda Hart WEBER ${ }^{2}$, Yoon Kil CHANG ${ }^{2, *}$
}

\begin{abstract}
RESUMO
O presente trabalho tem como objetivo determinar a influência das interações das gomas xantana e guar com o amido de milho de alto teor de amilose na textura de gel durante o armazenamento. Foram utilizadas amostras de amido milho Hylon VII ${ }^{\circledR}(71 \%$ de amilose, National Starch, goma guar (Higum 55I ${ }^{\circledR}$, Rhodia) e goma xantana (Rhodigel 200 ${ }^{\circledR}$, Rhodia). Foram utilizadas diferentes concentrações das gomas guar e xantana, que variaram de 0 a $1 \%$, de acordo com o delineamento experimental central composto rotacional. Em cada tratamento foram utilizadas $50 \mathrm{~g}$ de amido com alto teor de amilose (Hylon VII), adicionadas das gomas. Estas amostras foram diluídas em água destilada e submetidas à agitação mecânica até completa dissolução. As soluções foram aquecidas até $95^{\circ} \mathrm{C}$ por 5 minutos para formação dos géis, os quais foram acondicionados em recipientes plásticos de $50 \mathrm{~mL}$ e mantidos em temperatura de $5-10^{\circ} \mathrm{C}$ até $120 \mathrm{~h}$. Nos tempos T1 (24h), T2 (48h), T3 (72h), T4 (96h) e T5 (120h) de armazenamento foram feitas medidas da força máxima do gel de amilose em texturômetro (Stable Micro-System, Modelo TAX-T2). No período inicial, de 24 horas, a goma guar não apresentou influência positiva na redução da força do gel, sendo que a aplicação de goma xantana entre 0,7 e $1,0 \%$ apresentou os menores valores de força do gel de amilose. Após $120 \mathrm{~h}$ de armazenamento, a força do gel de amilose diminuiu com a adição de 0,5-1,0\% de goma xantana e 0-0,15\% de goma guar.

Palavras-chave: gel de amido; goma guar; goma xantana; textura.
\end{abstract}

\section{SUMMARY}

INFLUENCE OF HYDROCOLLOIDS IN TEXTURE OF CORN STARCH GEL The main objective of this study was to determine the influence of the interactions between guar and xanthan gums with high amylose content corn starch on the texture of the gel during storage. The samples used were Hylon VII ${ }^{\circledR}$ corn starch (71\% amylose) (National Starch), Guar gum (Higum 551®, Rhodia) and Xanthan gum (Rhodigel 200®, Rhodia). A central composite rotational design was used to formulate gels with different concentrations of the guar and xanthan gums, from 0 to $1 \%$. For each treatment, $50 \mathrm{~g}$ of high amylose content starch (Hylon VII) were added to the gums, which were then diluted with distilled water and mechanical mixed until completely dissolved. The suspensions were then heated to $95^{\circ} \mathrm{C}$ for 5 minutes to form gels, which were filled into $50 \mathrm{ml}$ plastic pots and kept at refrigeration temperatures $\left(5-10^{\circ} \mathrm{C}\right)$ for $120 \mathrm{~h}$. After 24 hours (T1), 48h (T2), 72h (T3), 96h (T4) and 120h (T5) of storage, the maximum gel strength of the starch gels was measured on the Stable Micro-System Model TAX-T2 texturometer. After the first 24 hours, the guar gum showed no positive influence on the reduction in gel strength, whereas the application of $0.7-1.0 \%$ xanthan gum showed the lowest values for the starch gel strength. During $120 \mathrm{~h}$ storage, the amylose starch gel strength was minimized by the use of $0.5-1.0 \%$ xanthan gum or by $0-0.15 \%$ guar gum.

Keywords: starch gel; guar gum; xanthan gum; texture.

\section{1 - INTRODUÇÃO}

O grânulo de amido, constituído por dois polissacarídeos, a amilose e amilopectina, pode ser submetido ao processo de formação do gel, que consiste no aquecimento de uma solução de amido-água até temperatura de $60-70^{\circ} \mathrm{C}$. Durante esse fenômeno ocorre a ruptura das estruturas cristalinas do grânulo de amido, o qual absorve água e entumece irreversivelmente, adquirindo tamanho maior que o original. Após a gelatinização do amido, quando a temperatura é reduzida à temperatura ambiente, ocorre um rearranjo das moléculas por ligações de hidrogênio, fator que favorece a recristalização [6], a retrogradação.

A retrogradação do amido é um fenômeno que deve ser minimizado por se tratar da reconstrução de uma estrutura mais rígida devido às cadeias de amilose ficarem mais disponiveis para se rearranjarem durante o shelf-

1. Recebido para publicação em 25/04/2003. Aceito para publicação em 05/07/2004 (001115).

2. Departamento de Tecnologia de Alimentos - Universidade Estadual de Campinas (UNICAMP). Caixa Postal 6121, CEP: 13083-970. Campinas, SP.

* A quem a correspondência deve ser enviada. life do produto alimentício, resultando em maior perda de água do sistema e endurecimento do produto final.

Os hidrocolóides são, em sua maioria, de ocorrência natural, solúveis em água e têm propriedades espessantes e/ou gelificantes em condições específicas [8]. A goma guar é uma galactomanana formada por cadeias lineares de unidades de D-manopiranosil ligadas entre si por ligações $\beta(1->4)$ e unidades de D-galactopiranosil, ligadas entre si por ligações $\alpha(1->6)$. Essa goma forma dispersões coloidais quando hidratada em água fria. É também muito utilizada em produtos de panificação para aumento de viscosidade e aumento de volume [3]. A goma xantana é um polissacarídeo extracelular produzido pela bactéria Xanthomonas campestris. É constituída de uma cadeia principal de unidades de D-glucose unidas entre si por ligações $\beta(1->4)$ com resíduos alternados de D-manose e ácido D-glicurônico, na proporção molar de 2:1, formando a cadeia lateral [4].

As gomas ou hidrocolóides são amplamente utilizados como aditivos na tecnologia de alimentos e têm como funções a melhoria da textura, retardamento da retrogradação do amido, aumento da retenção de umidade, enfim, a melhoria da qualidade, em geral, dos produtos de panificação. O principal efeito produzido pelos hidrocolóides é o atraso da retrogradação da amilose pela for- 
mação de complexos entre os hidrocolóides e as cadeias da amilose [7].

A incorporação de hidrocolóides em soluções de amido modifica as propriedades reológicas e causa aumento da viscosidade. Por este motivo, as gomas são utilizadas para conferir estabilidade a produtos como pudins e sobremesas. Estudos sobre a interação de amido de milho a 5\% com goma guar e LBG (goma locusta) nas concentrações de $0-0,2 \%$, mostraram que à medida que aumenta a concentração dos hidrocolóides diminui a temperatura de gelatinização e aumenta a viscosidade a frio da solução [9].

Estudos recentes de sistemas contendo hidrocolóides e amidos sugerem a ocorrência de um efeito sinérgico entre esses ingredientes. Os fatores que interferem nesta interação e, como ocorre ainda não estão totalmente esclarecidos, mas há evidências de que os hidrocolóides promovem maior estabilidade de géis de amidos [9].

Alguns trabalhos estão direcionados no sentido de esclarecer o exato mecanismo de interação entre os hidrocolóides e os componentes do amido [7].

O presente trabalho tem como objetivo, determinar a influência das interações das gomas guar e xantana com o amido de milho de alto teor de amilose em relação à textura de gel durante o armazenamento.

\section{2 - MATERIAL E MÉTODOS}

\section{1 - MATERIAL} Starch

Amido de milho Hylon $\mathrm{VII}^{\circledR}$ (71\% de amilose), National

Goma Guar (Higum 55I ${ }^{\circledR}$, Rhodia)

Goma Xantana (Rhodigel 200 ${ }^{\circledR}$, Rhodia)

\section{2 - MÉTODOS}

\subsection{1 - Preparo dos géis de amilose}

Em cada tratamento que consta na Tabela 2, $50 \mathrm{~g}$ de amido com $71 \%$ de amilose (Hylon VII) foram adicionadas às gomas guar e xantana de acordo com o planejamento experimental fatorial completo; as amostras foram então suspensas em água destilada até completar $1000 \mathrm{~mL}$ de suspensão e submetidas à agitação mecânica até completa dissolução. As soluções foram aquecidas até $95^{\circ} \mathrm{C}$ por 5 minutos para formação dos géis. Alíquotas foram acondicionadas em recipientes plásticos de $50 \mathrm{~mL}$ e mantidas à temperatura de refrigeração $\left(5-10^{\circ} \mathrm{C}\right)$ até $120 \mathrm{~h}$.

\subsection{2 - Avaliação de textura dos géis de amilose}

Nos tempos T1(24h), T2(48h), T3(72h), T4(96h) e T5(120h) de armazenamento foi medida a força máxima dos géis de amilose no Texturômetro Stable MicroSystem, Modelo TAX-T2 com sonda cilíndrica de acrílico, número $\mathrm{P} / 5 \mathrm{R}$, em temperatura ambiente, usando profundidade de penetração de $8 \mathrm{~mm}$ e velocidade de $0,5 \mathrm{~mm} / \mathrm{s}$. As medidas foram feitas em quintuplicatas.

\subsection{3 - Planejamento experimental e análise estatística}

O planejamento experimental, segundo BOX \& WILSON [1] foi aplicado para determinação da influência de interações entre hidrocolóides em géis de amilose. As variáveis foram estabelecidas em três níveis codificados como $-1,0,+1$. Os valores reais correspondentes a estes niveis encontram-se na Tabela 1 . As variáveis e os niveis de variação foram estabelecidos de acordo com os limites tecnológicos do uso de hidrocolóides e com a bibliografia.

Foram realizados 11 tratamentos, quatro fatoriais (combinação dos níveis $-1 \mathrm{e}+1$ ), quatro axiais (uma variável no nível $\pm \alpha$ e a outra em 0 ), três centrais (as duas variáveis no nível zero). Os pontos de nível zero estão posicionados no centro de um círculo de raio um (1) e servem para estimar o erro experimental e determinar a precisão da equação de regressão [2].

As determinações de textura foram realizadas nos tempos T1 (24h), T2 (48 h), T3 (72 h), T4 (96 h) e T5 (120 h) para avaliar o comportamento das amostras durante o "shelf-life".

TABELA 1. Variáveis e níveis de variação do experimento de gel de amilose

\begin{tabular}{|c|c|c|c|c|c|}
\hline \multirow{2}{*}{$\begin{array}{c}\text { Variáveis } \\
\text { Independentes }\end{array}$} & \multirow[b]{2}{*}{$-\alpha$} & \multicolumn{3}{|c|}{ Níveis de variação } & \multirow[b]{2}{*}{$+\alpha$} \\
\hline & & -1 & 0 & +1 & \\
\hline GG:goma guar & 0 & 0,15 & 0,5 & 0,85 & 1 \\
\hline GX: goma xantana & 0 & 0,15 & 0.5 & 0,85 & 1 \\
\hline
\end{tabular}

$\alpha= \pm 1,414$ para $\mathrm{K}=2$ (duas variáveis independentes).

TABELA 2. Delineamento experimental central composto rotacional para duas variáveis e três níveis utilizados no experimento de gel de amilose

\begin{tabular}{l|c|c|c|c}
\hline \multirow{2}{*}{ Tratamento } & \multicolumn{2}{|c|}{ Codificada } & \multicolumn{2}{c}{ Real $(\mathrm{g} / 100 \mathrm{~mL})$} \\
\cline { 2 - 5 } & $\times 1$ & $\times 2$ & $\mathrm{X} 1$ & $\mathrm{X} 2$ \\
\hline 1 & -1 & -1 & 0,15 & 0,15 \\
2 & 1 & -1 & 0,85 & 0,15 \\
3 & -1 & 1 & 0,15 & 0,85 \\
4 & 1 & 1 & 0,85 & 0,85 \\
5 & $-\alpha$ & 0 & 0 & 0,50 \\
6 & $+\alpha$ & 0 & 1 & 0,50 \\
7 & 0 & $-\alpha$ & 0,5 & 0 \\
8 & 0 & $+\alpha$ & 0,5 & 1 \\
9 & 0 & 0 & 0,5 & 0,5 \\
10 & 0 & 0 & 0,5 & 0,5 \\
11 & 0 & 0 & 0,5 & 0,5 \\
\hline Padrão & - & - & 0 & 0 \\
\hline
\end{tabular}

$\alpha= \pm 1,414$ para $\mathrm{K}=2$ (duas variáveis independentes).

Valor codificado: $\mathrm{x} 1$ : goma xantana, $\mathrm{x} 2$ : goma guar; valor real: $\mathrm{X1}$ : goma xantana; $\mathrm{X} 2$ : goma guar.

\section{3 - RESULTADOS E DISCUSSÃO}

Na Figura 1 pode-se verificar a evolução da dureza do gel de amilose, representado pela força (g) em função do tempo de armazenamento. 
O ensaio padrão, que não contém hidrocolóides adicionados, resultou em alta força de gel no T1 (24h), ficando abaixo apenas dos tratamentos 4 e 8 , respectivamente, onde houve adição das maiores concentrações de goma guar $(0,85$ e $1 \%)$ e goma xantana $(0,85$ e $0,5 \%$ ), respectivamente, somado ao fato de as combinações destes dois hidrocolóides estarem na máxima concentração final (1,7 e 1,5\%). Isso exclui a possibilidade de os hidrocolóides terem aumentado a retrogradação da amilose, visto que os valores iniciais de força do gel já eram altos, devido a sua alta viscosidade.

Ao comparar os tratamentos com o padrão é possível observar que o ensaio 7 , com $0,5 \%$ de goma xantana, apresenta uma evolução linear de força do gel, demonstrando que este hidrocolóide minimiza a retrogradação do gel de amilose. No T5(120h) o padrão apresentou maior dureza com força média de 23,62g comparado com o tratamento 7 , com valor médio de $6,85 \mathrm{~g}$.

O tratamento $2(0,85 \%$ de xantana e $0,15 \%$ de guar $)$ comparado com o tratamento $3(0,15 \%$ de xantana e $0,85 \%$ de guar) demonstra que à medida em que se aumentou a concentração da goma guar, na presença de alta concentração da goma xantana ocorreu aumento da força do gel. Da mesma forma, alta concentração de goma xantana em baixa concentração de goma guar resultou em redução da força do gel de amido (Figura 1 e Tabela 2).

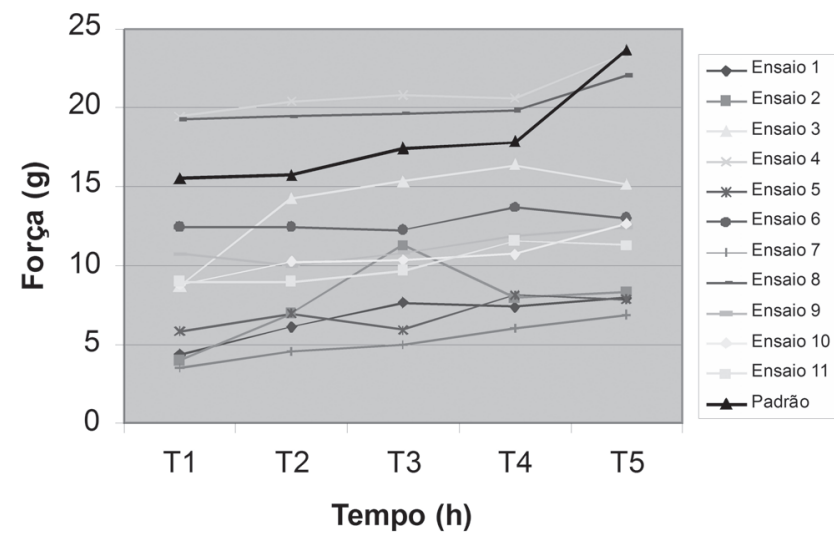

FIGURA 1. Força do gel de amilose em função do tempo de armazenamento

No presente trabalho, as análises de superfície de resposta foram realizadas para T1 (24h) e T5 (120h), pois, dessa forma, pode-se representar o momento inicial do "shelf life" e o tempo máximo de armazenamento dos géis, possibilitando demonstrar a evolução da rigidez dos géis de amilose, dependendo do sistema de hidrocolóides ( $\mathrm{x} 1$ = goma xantana e $\mathrm{x} 2=$ goma guar) presente no meio.

Com a análise dos dados, obteve-se o modelo matemático para as respostas dos tratamentos, fazendo uso do Software Statistica ${ }^{\circledR}$, seguem os modelos com os coeficientes significativos:

$$
\begin{aligned}
& \mathrm{T} 1=9,49+2,46 \times 1+5,26 \times 2+2,80 \times 1 \times 2 \\
& \mathrm{~T} 5=12,14+2,00 \times 1+5,49 \times 2+1,49 \times 2^{2}+2,01 \times 1 \times 2
\end{aligned}
$$

TABELA 3. Análise de variância para respostas de força de gel de amilose no T1(24h) e no T5 (120h)

\begin{tabular}{llllll}
\hline Respostas & Fontes de variação & g.l & SQ & MQ & Fcal. Ftab. \\
\hline T1 (24h) & Regressão & 3 & 300,79 & 100,26 & $63,46^{*} 4,35$ \\
& Resíduos & 7 & 11,04 & 1,58 & \\
& Falta ajuste & 5 & 8,74 & 1,75 & $1,52(\mathrm{~ns}) 19,30$ \\
& Erro puro & 2 & 2,30 & 1,15 & \\
\hline \multirow{2}{*}{ T5 (120h) } & Total & 10 & 311,83 & & \\
& Regressão & 4 & 304,95 & 76,24 & $74,75^{\star} 4,53$ \\
& Resíduos & 6 & 6,13 & 1,02 & \\
& Falta ajuste & 4 & 5,12 & 1,28 & $2,51(\mathrm{~ns}) 19,25$ \\
& Erro puro & 2 & 1,01 & 0,51 & \\
\hline & Total & 10 & 311,08 & &
\end{tabular}

T1(24h) e T5(120h) são significativos $(\mathrm{p}<0,05)$.Falta de ajuste não é significativa ao mesmo nivel de significância.

As informações contidas na Tabela 3 demonstram que os modelos codificados obtidos são válidos com valores de $\mathrm{R}^{2}$ : 96,46\% e $\mathrm{R}^{2}:$ 98,03\%, respectivamente.

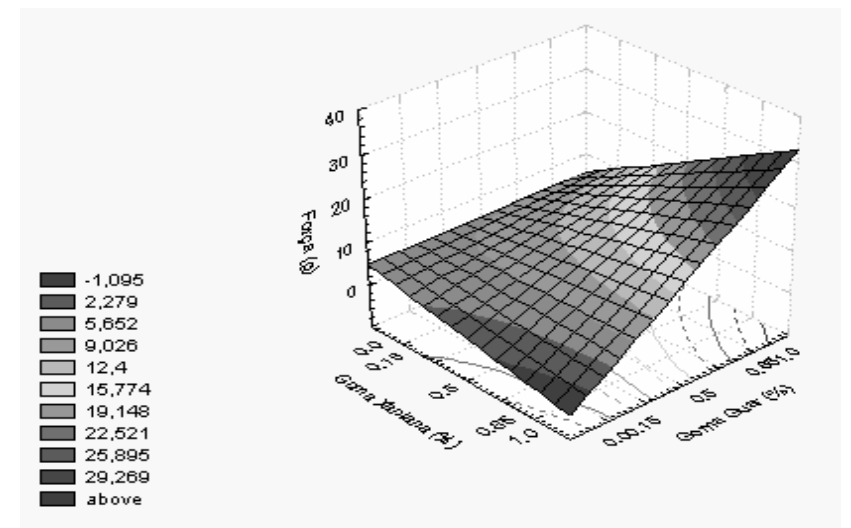

FIGURA 2. Efeito da concentração das gomas xantana e guar no força do gel no T1 (24 horas) de armazenamento.

A Figura 2 representa o gráfico de superfície de resposta correspondente ao modelo codificado para o $\mathrm{T} 1$ (24h), que estabelece a variação da força do gel de amilose em função da concentração das gomas xantana e guar.

Pelo gráfico, observa-se que os maiores valores de força do gel ocorreram em altas concentrações da goma guar, resultado esperado já que os hidrocolóides têm a propriedade de conferir maior firmeza aos produtos alimentícios. Como o objetivo do trabalho foi o de verificar se a adição de gomas no gel de amilose afetaria a força do gel, nas $24 \mathrm{~h}$ iniciais esse efeito foi fraco e ocorreu nas maiores concentrações de goma xantana e menor concentração da goma guar.

A Figura 3 representa o gráfico de superfície de resposta correspondente ao modelo codificado para o T5 (120h), que também estabelece a variação da força do gel de amilose em função da concentração das gomas xantana e guar. Mostra que os valores de força do gel variaram entre 7,19 e 33,98g. O menor valor de força do gel foi verificado no experimento com a maior concentração $(1,0 \%)$ da goma xantana e na menor concentração $(0,15 \%)$ da goma guar. Entretanto, aumento da con- 
centração da goma guar, independente da goma xantana, aumentou a força do gel.

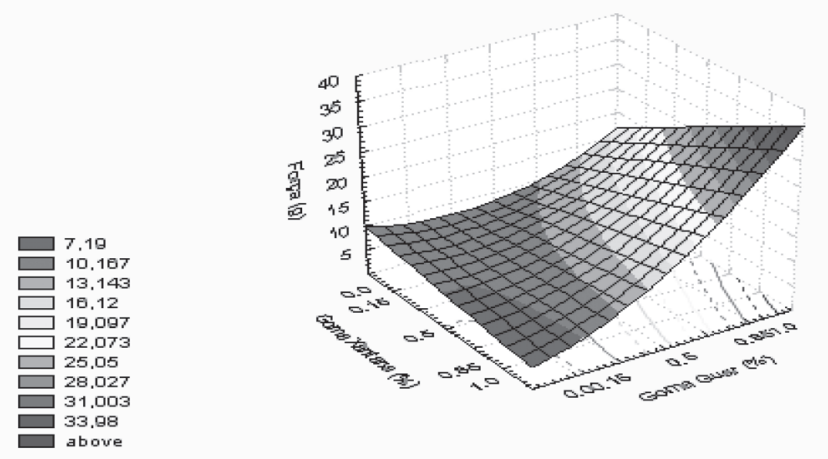

FIGURA 3. Efeito da concentração das gomas xantana e guar na força do gel no T5 (120 horas) de armazenamento.

Vários estudos estão sendo desenvolvidos para avaliação da adição de hidrocolóides em suspensões de amido, que comprovam a melhoria nas características dos produtos. Através do presente trabalho pôde-se verificar que, com relação à textura, ao serem incorporadas ao amido de milho com $71 \%$ de amilose, as gomas xantana e guar promoveram a diminuição da força do gel após 120h de armazenamento, principalmente pelo efeito exercido pela goma xantana. Isto quer dizer que, como a força é conseqüência da retrogradação das cadeias de amilose, os hidrocolóides reduziram este fenômeno que interfere negativamente na qualidade de produtos espessados com amido e que necessitam de refrigeração.

MANDALA, PALOGOU \& KOSTAROPOULOS [5] estudando o efeito da goma xantana em géis de amido de batata com relação à força (g) durante o armazenamento a $5^{\circ} \mathrm{C}$ também concluíram que esta goma contribuiu significativamente para a melhoria da textura dos géis no sentido de que promove uma diminuição da força dos géis.

SUDHAKAR, SINGHAL \& KULKARNI [10], estudaram a interação de amido de milho-goma xantana e amido de milho-goma guar e verificaram que os hidrocolóides conferiram maior estabilidade aos géis de amido pelo retardo da retrogradação e diminuição da sinerese.

\section{4 - CONCLUSÕES}

No período inicial, de 24 horas, a goma guar não apresentou influência positiva na redução da força do gel, sendo que a aplicação de goma xantana entre 0,7 e $1,0 \%$ apresentou os menores valores de força de gel de amilose.

Durante $120 \mathrm{~h}$ de armazenamento a $10^{\circ} \mathrm{C}$, a força do gel de amilose foi minimizada com o uso de 0,5-1,0\% de goma xantana e 0-0,15\% de goma guar. É possivel minimizar a força do gel com dosagem adequada de goma xantana em combinação com a goma guar, que apresenta menor custo.

\section{5 - REFERÊNCIAS BIBLIOGRÁFICAS}

[1] BOX, G.P.; WILSON, K.B. On the experimental attainment of optimum condition. Journal Royal Statistics, n. 13, p. 1-45, 1951.

[2] COChRAN, B.Y.;COX, G.M. Experimental Design. 2 ed. New York: John Wiley, 1964.

[3] GOLDSTEIN, A.M.; ALTER, E.N.; SEAMAN, J.KK. GUAR GUM: In: WHISTLER, R. (Ed) Industrial Gums. New York: Associated Press, 1973. p.315

[4] JANSSON, E.; KENNE, L.; LINDBERG, B. Structure of the extracellular polysaccharide from Xanthomonas campestris. Carbohydrate Research., v. 45, p. 275-282, 1975.

[5] MANDAla I.G., PALOGOU E.D., KOSTAROPOUlOS A. E. Influence of preparation and storage conditions on texture of xanthan-starch mixtures. Journal of Food Engineering, v. 53, p. 27-38, 2002.

[6] PARKER, R.; RING, S.G. Aspects of the physical chemistry of starch. Journal of Cereal Science, v. 34, p. 1-17, 2001.

[7] ROJAS, J.A.; ROSELL, C.M.; DE BARBER, C.B. Pasting properties of different wheat flour-hydrocolloid systems. Food Hydrocolloids, Amsterdam, v. 13, p. 27-33, 1998.

[8] STAUFFER, C.E. Functional Additives for Bakery Foods, p. 164-177, 1985.

[9] SUDHAKAR, V.; SINGHAL, R.S.; KULKARNI, P.R. StarchGalactomannan interactions: funcionality and rheological aspects. Food Chemistry, v. 55, n. 3, p. 259-264, 1996.

[10] SUDHAKAR, V.; SINGHAL, R.S.; KULKARNI, P.R. Effect of sucrose on starch hydrocolloid interactions. Food Chemistry v. 207, n. 2, 1998. 